\title{
Research on Inventory Management of Small and Medium-sized Manufacturing Enterprises in China under Supply Chain Environment
}

\author{
Zhou Fengjiao, Yin Xiuqing
}

Business School, Shandong University of Technology, Zibo 255000, China

\begin{abstract}
Most enterprises have problems of liquidity shortage and poor capital turnover. This is the pressure of funds caused by the large inventory of enterprises. Excessive inventory will not only occupy a large amount of corporate capital, but also cause a series of The extra cost of the product will increase the cost of the product; while the inventory is too small, it will not be able to meet the market demand in a timely manner, and it will not be able to cope with the complex market changes. The purpose is to solve these problems and find the optimal combination of inventory costs and inventory benefits. On top of these, coupled with the development of information technology, it is the general trend that companies take advantage of the advantages of supply chain management to scientifically manage their inventory.
\end{abstract}

Keywords - supply chain; inventory management; cost.

\section{PREFACE}

With the rapid development of the times, it is difficult for China's manufacturing companies to significantly improve the core technologies such as production technology and operation processes, and it is becoming more difficult to improve production efficiency. In order to cope with the current fierce competition, most companies the goal has shifted to the non-core but significant cost-increasing module-logistics. According to the compilation of public information, China's logistics accounted for gdp is still relatively high. In the first quarter of 2019 , the total social logistics of the country reached 66.5 trillion yuan, an increase of $6.57 \%$ year-on-year The total cost of social logistics is 3.1 trillion yuan, accounting for $14.52 \%$ of the GDP.The proportion of CDP has been declining for many years, but compared to less than $10 \%$ in the United States, Japan, and Germany, there is still much room for development in China's logistics industry. From a development perspective, the idea of improving from a logistics perspective is achievable.

Generally speaking, the logistics cost of an enterprise includes four major sections, namely procurement, warehousing, inspection and logistics. The management and control strategy of the enterprise warehouse will directly affect the cost of procurement and inspection of parts and components by the enterprise, and then affects logistics costs. Therefore, it makes enterprises pay more attention to the management of inventory. With the development of supply chain theory in recent years, the extension of time and space brought by the supply chain has made the enterprise's optimized management of inventory more diversified. Inventory management is also an important part of supply chain management. Enterprises should effectively use the control and information of information flow, logistics and cash flow in the supply chain to maintain a balanced inventory and order times. On the one hand, maintain a proper amount of inventory. On the one hand, to ensure the rational use of funds, to avoid the situation where a large amount of funds are occupied by inventory, so as to improve production efficiency and sales revenue. Maintaining the best inventory under the premise of ensuring production quality and timely supply is the most urgent need of enterprises to solve. Problems are also an 
effective way to reduce corporate costs.

\section{STATUS OF INVENTORY MANAGEMENT IN SMALL AND MEDIUM-SIZED MANUFACTURING ENTERPRISES}

Due to the limitation of enterprise scale, small and medium-sized manufacturing enterprises cannot implement advanced inventory management models such as zero inventory or storage type implemented by large enterprises.The enterprise manages its own inventory and does not involve third parties, so it still relies heavily on it. The experience of the general manager of the enterprise to manage the inventory belongs to the category of experience management. The general manager's influence in this type of enterprise is quite large.It plays a decisive role in both the operation of the enterprise and the management of various links. The status of its inventory management also depends on the importance and attitude of the general manager.

\subsection{Excessive pressure on three funds in inventory and analysis of reasons}

Small and medium-sized manufacturing enterprises generally face excessive pressure on three funds, which seriously affects the capital turnover of enterprises.

The reasons are as follows:

(1) Due to the gradual distortion of information transmission in the supply chain, enterprises are not allowed to predict demand, which increases the purchase of raw materials and increases the pressure on inventory.

(2) The advance pre-purchase period for some raw materials is too long, which increases the order quantity of raw materials, resulting in an increase in raw material inventory.

(3) The market we face is constantly changing, and the orderer may change or cancel the order if the market changes. If the raw materials have been stored in the warehouse, or are already in production, or have been produced, even the sudden change will be subject to the other party's penalty. Compensation, but raw materials, work in progress, and finished goods in stock will still increase.

(4) Improper communication between various departments within the company, errors in information exchange, resulting in a mismatch between output and sales, overproduction, and redundancy in finished products.

(5) The procurement periods of various raw materials are different. Without one, the production and assembly of the product cannot be completed, which causes the waiting period of some links to increase. In this case, the inventory of work in progress will be increased.

(6) The company's product brands and models are diverse.For most purchasers, they will not only buy a single product. Therefore, according to customer needs, the company needs to stock various products and send them to the purchaser after the distribution is complete. This has caused an inevitable backlog of finished product inventory, and even affected delivery, causing the loss of customers.

(7) Poor universality of raw materials. Most companies have multiple types of products, so the specifications of the raw materials are also very different, because considering the purchase and transportation costs, even if the minimum purchase batch is purchased, the various accumulations will increase the inventory. , Taking up funds.

\subsection{Low inventory turnover rate and reasons}

The inventory turnover rate is an indicator that reflects the speed of the company's products and capital flow, and the low turnover rate largely indicates that the company's goods circulation speed is slow, which means that it takes a long time to obtain profits and therefore restricts the development of enterprises. There are situations where inventory turnover is low.

The reasons are as follows:

(1) The company mainly relies on orders for production, but the time from accepting the order to generating the raw material purchase order is too long. After receiving the customer order, the company plans to purchase staff based on the existing finished products, work in process, and raw materials in the warehouse. According to the actual conditions, a purchase order is generated for the demand for each raw material, and the purchaser starts the purchase according to the order. This process is generally long because the inventory information is not fixed and the warehouse materials are always in a flowing state, making it difficult for the plan purchaser to distinguish The specific use of materials, and secondly, the inaccuracy of some 
information in the enterprise because it is not shared in a timely manner, these all make the time for generating purchase orders longer.

(2) The procurement cycle of some raw materials is long.

(3) The inventory backlog caused by various reasons has also reduced the inventory rotation rate to a certain extent.

(4) The purchaser delays the delivery. Because the seller also has its own inventory, sometimes because of changes in the market, the seller's own inventory is left, but the forecasted order has been submitted to the manufacturer, and the product has been output, and the purchaser It delayed the pickup for various reasons to maintain the rationality of its inventory, but it caused the manufacturer's inventory rotation rate to be low.

\subsection{Customer Satisfaction Failure Analysis and Reason}

\section{Analysis}

After analyzing the feedback from the questionnaire survey of the major customers, it was found that customer satisfaction did not reach the desired goal.If these problems were not resolved in a timely manner, it would affect the company's credibility, which would have a negative impact on sales and cause more inventory backlogs. as follows:

(1) Failure to ship in time. Mainly due to unreasonable production plans and failure to produce all products required by customers in a timely manner. Because customers' orders will not be a single product, but will require multiple product combinations, and the products on the order As long as one of them is not completed on time, it cannot be shipped according to customer requirements. If you choose to distribute to the customer in batches, that is, to send the completed product to the customer first, and the remaining reissue will not only increase the transportation cost, but also the customer may Some products are out of stock and cannot be assembled and used, which causes dissatisfaction with the company.

(2) Incorrect delivery. The types of incorrect delivery mainly include the wrong product model, the lack of some products, and the lack of a certain number of products. The responsibility of the dispatcher is very important. Once negligent, it will cause some irreparable losses. If you send the wrong goods, you will first reduce your trust in the company and return the goods. The good situation is to give you a chance to re-ship. If you directly return the goods to cancel the order, it will mean that you will lose customers. .

(3) Packaging problems. First, the packaging is not strong enough, and it is damaged during transportation. Second, the packaging is not installed in the way required by the customer.

(4) Product quality issues. First, the quality inspection staff did not detect defective products in a timely manner; second, there is still room for improvement in production technology; third, the impact of warehouse facilities and the environment on the product; fourth, poor packaging Wear; Fifth, the damage to the product caused by insufficient protection measures during transportation.

(5) Transportation problem: The transportation is not carried out in the way requested by the customer.

\subsection{Corporate personnel's weak awareness of inventory management informatization}

Grass-roots personnel are not highly involved in the overall development of the enterprise, and will only be subject to the orders of their superiors, regardless of right or wrong, only implementation, lack of judgment and courage to reflect the problem upwards. The slow progress of inventory management informatization also stems from corporate leadership And employees' weak awareness of inventory management. First of all, the upper layers of the company do not pay enough attention to inventory management. Secondly, the leaders of the company and the grassroots employees simply believe that the informationization of inventory management is the initial collection of information on the computer, and the accounting is done through the computer. Such a preliminary understanding of operation lacks a profound understanding and attempt of informatization of inventory management. This makes it impossible for leaders of the company to understand all kinds of information in real time, dynamically, and efficiently, despite the implementation of informatization management in name. Nor has it been able to achieve the sharing of inventory information resources between departments and departments, between departments and employees, between departments and 
suppliers. The situation where the book data does not match the actual inventory has not been discovered and improved in a timely manner, resulting in a large number of potential losses. This is the case for most SMEs.

\subsection{Enterprises' inventory management has not reached the strategic area of the supply chain environment}

Most of the enterprise's inventory management stays inside the enterprise.The enterprise's inventory management basically belongs to the category of experience management.The general manager of the enterprise plays a decisive influence in all aspects of the operation and management of the enterprise. His attitude towards the inventory management also determines The status of enterprise inventory management, such experience management has great personal subjectivity, it is easy to form inherent thinking, lack innovation, and easily fall behind. The lack of information sharing among various companies in the supply chain is also a major culprit in increasing enterprise inventory. So According to the basic principles of inventory management in the supply chain environment, the available resources between the upstream and downstream of the supply chain should be reasonably deployed, the door of information sharing should be opened, and a point-to-chain and chain-to-plane inventory management model should be created to improve work efficiency. To reduce the cost and loss of sluggish inventory.

\section{EFFECTIVE MEASURES OF ENTERPRISES FOR INVENTORY MANAGEMENT}

Aiming at the common problems in China's small and medium-sized manufacturing enterprises, the following points are given on effective measures for inventory management:

(1) Improve warehouse management. The placement of materials should follow the following principles: avoid unnecessary handling and movement; first-in, first-out (considering the reasons for the shelf life); facilitate the identification of goods, facilitate access, avoid damage, and reasonably use the warehouse area.

(2) Strengthening the construction of enterprise informationization. Informationization construction is necessary for the long-term development of an enterprise.
Informationization construction can not only manage inventory more efficiently, but also timely feedback information to various departments to strengthen the On the other hand, you can also communicate with suppliers with high efficiency to shorten the meeting time and reduce costs. Strengthening informationization makes it easier to introduce advanced inventory management technologies, such as RFID technology. This technology can be used in Quickly read the information of raw materials when entering and leaving the warehouse, and record the read data into the computer, so that the raw materials can be effectively monitored.

(3) Improve the inventory turnover rate. Some suggestions for improving the inventory turnover rate: Strictly control the amount of main materials and strengthen the connection of various production processes, so that the speed and efficiency of material turnover are improved, and it can be put into sales quickly; slow-moving products and senior Inventory price reduction; promote sales and productivity; use advanced information technology to shorten the time from receiving an order to generating a raw material purchase order; shorten the cycle; formulate guidelines, non-special reasons purchasers must not delay delivery.

(4) The supply chain procurement model is adopted. Traditional procurement management is based on inventory procurement. The information of enterprises at all levels is opaque, and it is difficult to avoid the problem of distortion or enlargement of demand information, which leads to high inventory. Under the supply chain procurement model, the supply and demand sides Through strategic partnerships, sharing of inventory data is realized, making purchasing decisions transparent, reducing the distortion of demand information, and reducing the risks caused by unpredictable demand changes. Making strategic purchase plans through joint negotiation.

(5) Select high-quality suppliers and establish long-term cooperative relationships with them. Good cooperative relationships between enterprises and suppliers are the key to the success of procurement strategies.

(6) Appropriate customer surveys. In order to be competitive in the same industry, it is necessary to clarify customer needs. Enterprises should give full play to their 
corporate advantages and, based on market grasp, investigate the needs of the supply department to clarify What the customer wants, then boldly conceive according to customer requirements, develop their own ideas, and continuously improve the enterprise. This will not only lay the foundation for their long-term development, but also better meet customer needs and improve customer satisfaction.

(7) Establish a strategic partnership of supply chain and improve the coordination between enterprises. The supply chain is a whole, which needs to coordinate the activities of various enterprises on the nodes to achieve the best operating results. The ability to establish its strategic partnership Strengthening the previous level of trust between each other, companies can also make better use of resources and information in the supply chain, making each other's information more transparent, thereby avoiding enterprises to maintain high safety stocks under uncertain demand, which can achieve The purpose of reducing corporate capital occupation.

\section{SUMMARY}

Standing in the context of the supply chain, the research on the inventory management of China's small and medium-sized manufacturing enterprises mainly includes four aspects, which are supplier-linked inventory, enterprise's own inventory, consumer-linked inventory, and resource utilization of the supply chain. Supplier-linked inventory is mainly aimed at improving procurement and selection of suppliers; the company's own inventory mainly includes warehouse use, information construction and inventory turnover rate; consumer-linked inventory mainly improves customer satisfaction; and resources in the supply chain Utilization is mainly achieved by improving the supply chain thinking of enterprises and establishing strategic partners.

\section{REFERENCES}

[1] $\mathrm{Hu}$ Jianbo, Chen Min. Supply chain inventory management strategy [j]. Enterprise Management, 2013 (04): 66-68.

[2] Lin Lihua. Application of Lean Production Theory in Supply Chain Inventory Management [j]. Xiamen Science and
Technology, 2013 (03): 54-57.

[3] Gao Xiaowei. Research on inventory management optimization of c automobile sales company under supply chain environment [d]. Hebei University, 2019.

[4] Yang Yanling, Tian Yu. Research on the Impact of Supply Chain Management Practices and Supply Chain Agility on Enterprise Performance [j]. Business Economics and Management, 2015 (09): 13-19 + 96.

[5] Luo Exiang, Wang Rongrong, Wu Haikuan. Supply chain concentration, inventory management, and operating performance of small and medium-sized manufacturing enterprises [j]. Technology and Innovation Management, 2020, 41 (02): 197-202.

[6] Nie Fuquan, Yang Wenli. Principle and implementation process of jit procurement model [j]. Mechatronics, 2005 (05): 11-15.

[7] Wang Peng. Research on h company procurement management based on material classification [d]. Xi'an University of Architecture and Technology, 2014.

[8] Zhan Baizhong. On the Optimization of Inventory Management in Production Enterprises [j]. Commercial Economy, 2019 (09): 106-107.

[9] Allen R. Reders. "Procurement and Supply Management Process" [m]. Beijing: Electronic Industry Press, 2005.

[10] Chen Hanqing. On the inventory management method of enterprises [j]. Sichuan Cement, 2018 (02): 202. 